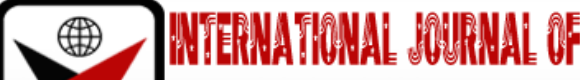

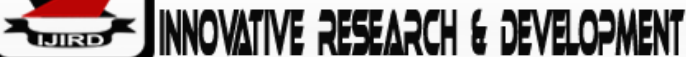

ISSN 2278-0211 (Online)

\section{Teachers' Self-efficacy and Implementation of the Ghanaian Language and Culture Curriculum}

\author{
Margaret Gifty Bassah
}

Teacher, Department of Arts Education, University of Cape Coast, Ghana

\begin{abstract}
:
This study aimed at exploring the perceived efficacy beliefs of teachers in implementing the Ghanaian Language and Culture curriculum in the North and South Danyi District of the Volta region. To achieve this, the descriptive survey research design was adopted for the study. Data was collected through a questionnaire and analysed with descriptive (Means and Standard Deviation) and inferential statistics (Independent Samples t-test, ANOVA, and Regression). The study revealed that Ghanaian Language teachers exhibited a high sense of efficacy in implementing the Ghanaian language and Culture curriculum. It was further established in this study that the self-efficacy beliefs of the Ghanaian Language teachers predicted their fidelity in implementing the Ghanaian language and Culture curriculum. Finally, the study found no statistically significant difference in the self-efficacy beliefs among Ghanaian Language teachers based on gender, age, and teaching experience.
\end{abstract}

Keywords: Ghanaian language, curriculum, self-efficacy, ewe, fidelity, senior high schools

\section{Introduction}

\subsection{Background to the Study}

Curriculum implementation plays an integral part in the development process of every curriculum and thus, without successful implementation, the school curriculum would remain mere ideas and policies. Curriculum Implementation, according to Oliva (1992) has to do with putting into practice curriculum plans and policies.Thus, every curriculum starts as a plan andonly becomes a reality when teachers put it into action. This suggests that careful planning and development of the curriculum would be worthless unless teachers have the knowledge and confidence and right notion (perception) to implement the curriculum in their classrooms (Marsh, 1997; Leung, 2008). As such, Marsh and Willis (2007) believe that teachers play an integral role in the development and implementation of every curriculum. It could, therefore, be concluded that that effective curriculum implementation relies on classroom instruction, teacher competencies, and their beliefs (Mazze, 2013).

It is worth noting that teachers' perceived confidence (henceforth, self-efficacy) is a prerequisite to the effectiveness of curriculum implementation (Smith, 1996). Perceived self-efficacy relates to the teachers' perceived confidence in how well they can accomplish a given academic task (Bandura, 1982). This perceived confidence, according to (Bandura, 1997), can significantly influence the success of teachers instructional practices. Most researchers suggest that self-efficacy influences an individual's goals, effort, choice of activities, and persistence (Bandura, 1997, Dibapile, 2012). Specifically, studies have brought to light the fact that teachers' self-efficacy is closely associated with teachers'teaching commitment (Coladarci, 1992), planning and organization of classroom (Allinder, 1994; Dibapile, 2012), management of classroom (Poulou, 2007; Woolfolk \& Hoy, 1990; Woolfolk, Rosoff, \& Hoy, 1990), and job satisfaction (Caprara, Barbaranelli, Borgogni, \&Steca, 2003). Moreover, teacher self-efficacy beliefs have been linked with teacher zeal to implementing new teaching techniques (Guskey, 1988; Czerniak\&Chiarelott, 1990; Ghaith\&Yaghi, 1997), and student motivation (Midgley, Feldlaufer\& Eccles, 1989).

Based on the aforesaid, it is worth mentioning that teachers with a higher sense of self-efficacy are more likely to excel in creating an enabling teaching and learning environment to foster the successful implementation of a given curriculum (Allinder, 1994; Bandura, 1997; Milner, 2001; Gibson \&Dembo, 1984; (Tschannen-Moran \& Woolfolk-Hoy, 2001). As such, conducting research that aims at assessing teachers' self-efficacy beliefs should be considered a necessity.

\subsection{Research Problem}

Scholars (Tschannen-Moran \& Woolfolk-Hoy, 2001; Wolters \& Daugherty, 2007) contend that effective curriculum implementation is somewhat contingent on the efficacy beliefs of teachers. This implies that efficacy beliefs are predictors of innovative teaching methods which in turn influence instructional effectiveness and successful student learning. Given this, scholars in various fields of study, particular in Ghana, have attempted to examine the self-efficacy of teachers and the extent of curriculum implementation. Generally, most of these studies conclude that self-efficacy predicts teachers' fidelity 
to curriculum implementation. Nonetheless, most of these studies focused on other subjects like Science, Mathematics, English Language, Social Studies, RME, and History (Eminah, 1993; Mereku, 1995; Okrah, 2002; Torto, 2017; Asare-Danso, 2011; Cobbold, 1999). In the Ghanaian language discipline, however, literature in this regard is limited; as such, this current study seeks to fill this gap by exploring teachers' perceived self-efficacy beliefs and their perceived fidelity in implementing the Ghanaian Language and Culture curriculum in the Senior High Schools in the Volta Region

\subsection{Research Objectives}

The study was guided by the following research objectives:

- To examine GHL teachers' perceived fidelity in implementationof the Ghanaian language and Culture.

- To examine GHL teachers' perceived self-efficacy beliefs in implementing the Ghanaian language and Culture curriculum.

\subsection{Research Hypothesis}

- $\mathrm{H}_{0}$ : There is no statistically significant effect of teachers' self-efficacy beliefs on curriculum implementation

- $\mathrm{H}_{0}$ : There is no statistically significant difference in the self-efficacy beliefs among GHL teachers based on gender, age, and teaching experience.

\section{Review of Related Literature}

\subsection{Theoretical Review}

The study is grounded in two theories: the Social Cognitive Theory (SCT by Bandura's (1977) and Fidelity Approach to curriculum implementation.

\subsubsection{The Self-Efficacy Theory}

Teacher Self-efficacy is a theoretical concept that has its roots in Bandura's Social Cognitive Theory (SCT). It is grounded on the premise that the teacher a professional being is endowed with the ability to facilitate instruction irrespective of the emotional state of the learner (Bandura, 1993; Tschannen-Moran \& Hoy, 2001). Hence, teachers with a higher sense of efficacy always perceive themselves as being capable of causing a behavioural change in their learners (Dibapile, 2012).

The major tenet of Bandura's SCT of learning is that people learn through their social interactions with others; thus teachers' self-efficacy in teaching could be developed by imitation, observation, and modelling. It is therefore believed that teacher competence could be improved when they are socially influenced. This social influence can be derived from the kind of motivation teachers get in their profession as a result of observing, imitating, or modelling their teaching practices around others in their profession. This means that teachers' may be enhanced through the kind of motivation they get from others, as well as the inspiration they get by watching others effectively executing their teaching functions.

\subsubsection{Fidelity Approach/Model of Curriculum Implementation}

This current study is rooted in the Fidelity approach to curriculum implementation. This theoretical perspective was considered appropriate for this study because the Ghanaian educational system advocates for strict adherence to the implementation of the curriculum planned disseminated by the National Council for Curriculum Assessment (NaCCA). This theoretical framework focuses on assessing how faithful teachers implement the curriculum as intended by the developers or sponsors of the program (Snyder et al., 1992). Hence, by using this as a theoretical basis for this current analysis, special attention would be paid to assessing the extent to which teachers of GHLare faithful in implementing the Ghanaian language curriculum.

\subsection{Empirical Studies}

This section reviews studies that have been conducted by other researchers on the phenomenon under investigation. This was achieved based on research questions and hypotheses formulated to direct the analysis.

\subsubsection{Perceived Self-Efficacy Beliefs and Effectiveness of Instructional Practices}

Literature abounds on the efficacy perceptions of teachers in developed and developing nations. Notable among most of these studies was a study by Bruce, Esmonde, Ross, Dookie, and Beatty (2010) who found that the efficacy of teachers goes a long way to influence the effectiveness of teachers in carrying out their instructional duties. The results of this study indicated that teachers with a higher sense of self-efficacy were more likely to excel in their effort to achieve the classroom objectives regardless of the challenges faced in accomplishing a learning task. Much as Bruce et al. (2010), Wolf, Foster, and Birkenholz (2010) also conducted a study that purported to examine the association between the self-efficacy of teachers who taught agriculture in the USA and the effectiveness they exhibit in executing the curriculum. With a sample size of 24 teachers at the University of Ohio, the study found that instructors indicated a high level of efficacy in teaching. Also, it was found that teachers' efficacy influenced their classroom practices because the teachers involved were found to be more effective in ensuring good classroom management, adopted effective and suitable learning strategies.

\subsubsection{Gender Difference in Teachers' Self-Efficacy Beliefs}

Kahraman, Yilmaz, Bayrak, and Gunes (2014) assessed the difference between gender regarding the self-efficacy and instructional effectiveness of science lessons. This study found no substantial differences between genders with 
respect to their self-efficacy believes and the effectiveness exhibited in executing the science curriculum. In the Caribbean, Jaggernauth and Jameson-Charles (2015) investigated three aspects of the efficacy of newly enrolled teachers pursuing a teacher development program in the Trinidad and Tobago universities. The study, specifically, aimed at the initial effectiveness of these teachers at the launch of the inception of the teacher development program (2013-2014). The instrument consisted of two sections: the demographic questionnaire and the Teachers' Sense of Productivity Scale (long form) (Tschannen-Moran \& Woolfolk Hoy, 2001). It was revealed that the efficacy of teachers was moderate. Also, the study found no significant difference between gender and years of teaching. However, it appeared in this same study that teachers over 45 years of age registered slightly greater teaching performance in classroom management than younger colleagues.

Despite the limited literature on efficacy-related research in the GHL subject area, there appear to be several studies in other fields. For instance, Sarfo, Amankwah, Sam, and Konin (2015) studied the association between the efficacy between gender and the school practices of teachers in high schools situated in the Kumasi metropolis. With a descriptive survey design and sample size of 259 male and 178 female teachers, the study indicated that the effectiveness of teachers for student engagement was greater than the effectiveness of classroom management and teaching methods. In all teachers reported comparatively higher self-efficacy. Based on these results, it was proposed that teacher training organizations concentrate on teaching educational strategies, student participation, and classroom management strategies to trainees in order to increase their effectiveness

In Ghana, Sarfo et al. (2015) conducted a relevant study that aimed at examining the relationship between gender and self-efficacy in classroom management and student engagement among teachers in high schools in the Kumasi metropolis. With a sample of 259 male instructors and 178 female instructors from both private and public SHS, the study revealed that in terms of instructional strategies, there was a significant difference between genders. Thus, female instructors employed effective instructional strategies than male instructors. On the other hand, there appeared to be no significant difference between males and females in terms of managing the classroom environment and also in engaging students. On the basis of these results, it was proposed that teacher training organizations concentrate on teaching instructional strategies, student participation, and classroom management strategies to trainees in order to increase their performance.

\section{Research Methods}

\subsection{Research Design}

The descriptive survey was employed for the study. This design was deemed appropriate for the study because it grants researchers the freedom to observe certain features, attitudes, emotions, values, motives, habits, views of a group that may be big or small, without trying to influence any variables (Osuala, 2001; Chalmers, 2004). As such, the design is considered the best fit owing to the fact that this study attempted to explore the efficacy beliefs of teachers regarding the implementation of the Ghanaian language and Culture curriculum in SHS in the North and South Danyi District.

\subsection{Research Participants}

The research took into account all GHLteachers in the SHS district of North and South Danyi in the Volta region of Ghana. There are nine (9) schools in the district of North and South (see Table 1). There were, on average, four (4) GHLteachers in each school. Some schools, however, also have five (5) teachers. The survey took into consideration all teachers situated in the North and South Danyi District of the Volta Region, Ghana. Thus, the census method was used to include all teachers because the number is limited and it is practical to include all teachers. The rationale for excluding other districts of the Volta Region in this study is that the North and South Danyi Districts is linguistically homogeneous; thus, the Ewe dialect they speak in these Districts is highly mutually intelligible, unlike the dialects of Ewe spoken in other Districts. Table 1 indicates the population distribution of the respondents.

\subsection{Data Collection Instrument}

The questionnaire was used as the key instrument for extracting data from respondents. The questionnaire was self-developed and adapted. The self-developed type is based on the allegiance of GHLteachers to the curriculum and the adapted type is based on the Teachers' Sense of Efficiency Scale (TSES) defined by Tschannen-Moran and Woolfolk Hoy (2001).

The questionnaire is a close-ended questionnaire of four (4) Likert Scale items ranging from strongly disagree to strongly agree. The questionnaire consists of four (4) parts (A, B, C \& D). Section 'A' provided data on the background characteristics (gender, age, and years of teaching experience) of the respondents. Section 'B' also elicited answers on the fidelity of GHLteachers in the execution of the program. Section ' $\mathrm{C}$ ' contains elements on GHLTeacher's sense of effectiveness in the execution of the program. Finally, section 'D' obtained data on the origins of the effectiveness of GHLteachers in the execution of the program. The research instrument was piloted using Senior High School teachers in Keta Municipality in the Volta Region of Ghana.

\subsection{Data Analysis Procedure}

Both descriptive and inferential statistics were used to interpret the results. The demographic profiles of the respondents were analyzed using frequencies and percentages. The first and second research objectives were analyzed using means and standard deviation, while research hypotheses i and ii were analyzed using inferential statistics (independent samples t-test and one-way ANOVA and regression analysis) 


\section{Results and Discussions}

\subsection{Demographic Data}

Table 1 shows the results of the respondents concerning the background characteristics. Regarding the gender distribution of respondents, it was found that out of 41 GHLteachers, 26 of them were male ( $n=26$; 63.4\%) while the remaining 15(26.6\%) were female. This result means that the male teachers are more than the female teachers. This could be attributed to the total number of GHLteachers in the North and South Danyi District of the Volta Region of Ghana.

\begin{tabular}{|c|c|c|c|}
\hline Variable & Sub-scale & Frequency & Percentage \\
\hline Gender & Male & 26 & 63.40 \\
& Female & 15 & 36.60 \\
\hline Age group & Between 30-34yrs & 4 & 9.80 \\
& Between 35-39yrs & 8 & 19.50 \\
& Between 40-44yrs & 10 & 24.40 \\
& Between 45-49yrs & 8 & 19.50 \\
\hline Academic qualification & From 50+ yrs. & 6 & 11.80 \\
\hline & Diploma/HND & 22 & 53.70 \\
& Bachelor's degree & 13 & 37.70 \\
\hline Teaching experience & Master's degree & 2 & 4.90 \\
& Between 1-5yrs & 18 & 43.90 \\
& Between 6-10yrs & 7 & 17.10 \\
\hline
\end{tabular}

Table 1: Background Characteristics of Respondents (N=41)

Source: Field Data, 2020

The age distribution of the respondents ranges from 30years to 50years and above, it was found that 11 (26.8\%) and $10(24.4 \%)$ of the respondents are within the age bracket of 50 years and above, and $40-44$ years respectively. This was followed by $8(19.5 \%)$ of the respondents a piece who indicated 45-49 years and 35-39 years respectively as their age bracket while only four of the teachers representing $9.8 \%$ were within the age bracket of $30-34$ years. This result suggests that the GHLteachers are experienced in terms of age. This result is important because it informs us about how GHLteachers build and increase their confidence level (self-efficacy) in curriculum implementation as they grow and mature in terms of age.

In Table 1, it was observed that the majority of the GHLteachers ( $n=22 ; 53.7 \%)$ had bachelor's degree while 13 $(37.7 \%)$ and $6(14.6 \%)$ of them had master's degree and Diploma/HND respectively. This result means that majority of the GHLteachers in the schools have the minimum qualification for the teaching profession; it is believed that they could acquire and develop some level of confidence during their initial training (Teacher Education Program) which could influence their fidelity in curriculum implementation. Concerning years of teaching experience, it was found out that 18 $(43.9 \%)$ of the respondents had taught for 6-10years. This was followed by $14(34.1 \%)$ and 7 (17.1\%) of the respondents who indicated that they had taught for 16-20years and 11-15years respectively. This result means that the GHLteachers are matured in terms of the number of years of experience in the teaching profession; they could provide us with valuable information on their self-efficacy beliefs and their effect on fidelity in curriculum implementation. It is believed that with the years of teaching experience, the GHLteachers could develop their self-efficacy level which could positively affect curriculum implementation in the school.

\section{Findings}

\subsection{GHL Teachers' Perceived Fidelity in the Implementation of the Ghanaian Language and Culture Curriculum}

The objective of research question one was to assess the perception of GHLteachers towards fidelity in curriculum implementation in senior high schools. The data was gathered using a questionnaire with a four-point Likert scale ranging from (1) strongly disagree to (4) strongly agree. The data was analyzed and discussed using Means and Standard Deviation. To judge the perception of GHLteachers towards fidelity in the curriculum implementation, a mean criterion was established based on the four-point Likert scale. A mean of 2.50-4.00 indicates respondents' positive perception while a mean of 1.00-2.49 indicates respondents' negative perception towards fidelity in curriculum implementation. The results are presented in Table 2. 


\begin{tabular}{|c|c|c|}
\hline Statement & Mean & SD \\
\hline I faithfully do exactly what GES indicated in the GHLteaching syllabus & 3.15 & 0.65 \\
\hline I faithfully use the instructional objectives indicated in the syllabus & 3.32 & 0.57 \\
\hline I strictly teach the content/subject matter as indicated in the syllabus & 2.85 & 0.91 \\
\hline I strictly follow the topics in the syllabus & 2.93 & 0.91 \\
\hline I strictly follow the prescribed teaching and learning activities in the syllabus & 2.90 & 0.63 \\
\hline I strictly use the recommended textbooks prescribed by GES or school & 2.78 & 0.99 \\
\hline $\begin{array}{c}\text { I exactly use the recommended teaching and learning strategies or methods prescribed } \\
\text { in the syllabus }\end{array}$ & 3.00 & 0.63 \\
\hline I use the proposed TLMs in the syllabus & 3.51 & 0.81 \\
\hline I use the time allocated on the school timetable & 2.90 & 0.80 \\
\hline Average Mean/SD & 3.10 & 0.70 \\
\hline I strictly follow the recommended assesment activities in the syllabus & 3.04 & 0.33 \\
\hline
\end{tabular}

Table 2: GHLTeachers' perceived Fidelity in Curriculum Implementation ( $n=41)$

Source: Field data, 2020

Table 2 presents the results of the GHLteachers concerning their fidelity in curriculum implementation. It is obvious from the results that GHLteachers are faithful in implementing the Ghanaian language and Culture curriculum in the SHS. They put the planned curriculum into action as intended by the authorities. For example, the GHLteachers used the proposed TLMs in the syllabus $(M=3.51 ; \mathrm{SD}=0.81)$. This result means that they faithfully used the recommended instructional resources/materials indicated in the teaching syllabus. They also used the recommended textbooks prescribed by GES or schools. The GHLteachers used the instructional objectives indicated in the syllabus (M=3.32; $\mathrm{SD}=0.57$ ). This result means that they faithfully set the instructional outcomes according to the recommended ones in the curriculum. This could help them provide instruction and select a plethora of instructional approaches that are tailored to the needs and interests of the students in the class.

It could also be inferred from the table thatGHLteachers strictly followed the recommended assessment activities in the syllabus ( $M=3.10 ; \mathrm{SD}=0.70)$, which implies that they faithfully adhered to the assessment principles and guidelines as indicated in the curriculum. Thus, they evaluate students learning based on the assessment procedures provided in the curriculum. Also, teachers strongly agreed that they use the recommended teaching and learning strategies or methods prescribed in the syllabus $(M=3.00 ; S D=0.63)$ and strictly followed the prescribed teaching and learning activities in the syllabus $(M=2.90 ; \mathrm{SD}=0.63)$. This result suggests that they faithfully adhered to the instructional strategies/pedagogies and activities stipulated in the curriculum. They could provide a variety of learning experiences that are valid, relevant, suitable, and comprehensive. They also revealed that they follow the topics in the syllabus $(\mathrm{M}=2.93 ; \mathrm{SD}=0.91)$ and teach the content/subject matter as indicated in the syllabus (M=2.85; $\mathrm{SD}=0.91)$. This result means that they faithfully delivered the subject matter to students as prescribed in the syllabus. They could demonstrate knowledge of the content and pedagogy in relation to the instructional objectives. Based on the aforementioned statistical results concluded from these results that, on average, the GHLteachers had a positive perception (MM= 3.04; $S D=0.33)$ towards their fidelity in implementing the curriculum in the senior high schools. Thus, they are highly faithful in setting instructional objectives, transacting the content, using instructional strategies, activities, resources, and assessment activities in the curriculum. These results, however, do not align with some of the prior researchers in Ghana. For example, Kwarteng (2013) indicated that basic school teachers' degree of fidelity in implementation of the 2007 Education Reform was not impressive. It also contradicts the findings of Owusu (2012) which suggest that there is a difference between the intentions of curriculum designers and teachers' implementation in that teachers were only able to implement the curriculum with moderate fidelity though they had the required qualification.

\subsection{GHL Teachers' Perceived Self-Efficacy Beliefs in Implementing the Ghanaian Language and Culture}

The objective of research question two was to examine the levels of self-efficacy beliefs among GHLteachers in the SHS. To judge the levels of self-efficacy beliefs among GHLteachers, a mean criterion was established based on the four point-Likert scale. A mean of 2.50-4.00 indicates respondents' high level of self-efficacy while a mean of 1.00-2.49 indicates respondents' low level of self-efficacy in curriculum implementation. The results are presented in Table 3. 


\begin{tabular}{|c|c|c|}
\hline Statements & Mean & SD \\
\hline Efficacy in Student Engagement & & 0.50 \\
\hline I can encourage students to step up in learning & 3.44 & 0.50 \\
\hline I can give students hope in whatever work they are doing & 3.42 & 0.49 \\
\hline I can give my student the edge to appreciate learning & 3.37 & 0.62 \\
\hline I can collaborate with parents to assist their wards in learning & 3.37 & \\
\hline Efficacy in Instructional Strategies & 3.68 & 0.61 \\
\hline I can craft good questions for 'my students during class tests and exams & 3.68 & 0.47 \\
\hline I can use a variety of assessment strategies for my students & 3.51 & 0.64 \\
\hline I can provide an alternative explanation or example when students are confused & 3.37 & 0.62 \\
\hline I can implement alternative teaching strategies in my classroom & & \\
\hline Efficacy in Classroom Management & 3.34 & 0.48 \\
\hline I can control disruptive behaviour in the classroom & 3.17 & 0.54 \\
\hline I can get my students to follow classroom and school rules & 3.20 & 0.68 \\
\hline I can calm a student who is disruptive or noisy in class & 3.15 & 0.62 \\
\hline I can establish a classroom management system with each group of students & 3.39 & 0.27 \\
\hline Average Mean/SD & & \\
\hline
\end{tabular}

Table 3: Levels of Self-Efficacy among GHLTeachers (N=41)

Source: Field data, 2020

It is obvious from the results that the GHLteachers had a high level of self-efficacy in implementing the curriculum. For example, concerning their efficacy in student engagement, it was found that they can motivate students who show low interest in school work $(M=3.44 ; \mathrm{SD}=0.50)$. This result means that the teachers could provide appropriate motivational strategies like captivating lesson introduction, establish rewards for progress, set appropriate goals and high expectations, and develop positive relationships that could increase and sustain students who show low interest in school work. They could also get students to believe that they can do well in school work $(\mathrm{M}=3.43 ; \mathrm{SD}=0.50)$. This result means that the teachers have the ability to create a robust culture for learning in which students will be made aware that they are capable of achieving excellence if they are prepared to work hard. This result means that they could motivate, inspire and encourage students to have confidence in their ability to excel in their academic work. Thus, they have the ability to influence students of their capabilities so that they can devote energy to the task at hand, and they take pride in their accomplishments. They could also help their students value learning $(M=3.37 ; \mathrm{SD}=0.49)$. This result means they could provide valid, relevant, and significant content and learning experiences that are important to the daily life of students. Thus, they have the ability to create a strong culture for learning where they will convey the educational value of what the students are learning. They could assist parents in helping their children to do well in school (M=3.37; SD=0.62). This result means that the teachers have the ability to provide guidance and assistance to parents on how to help their children to excel in their schooling. They could provide families with opportunities to partake in learning experiences, provide updates to families about the school curriculum and the individual success of students.

Further results indicated on the table seem to suggest thatGHL teachers had self-efficacy in instructional strategies. They had the confidence in their ability to craft good questions for their students during class tests and exams (M=3.68; $\mathrm{SD}=0.61$ ), which creates the impression that they have the potential to design high-quality questions that could lead students to consider and analyze, to expand their comprehension, and to test their theories against those of their classmates. Moreover, teachers were secure in their abilities to use a range of evaluation methods for their students $(M=3.68$; $S D=0.47)$; thus, they have the potential to put into practice effective evaluation practices that are aligned with students' learning standards. Teachers demonstrated that they had faith in their abilities to offer alternate interpretations for ideas or examples while students became frustrated during the teaching process $(\mathrm{M}=3.51 ; \mathrm{SD}=0.64)$. This results in the ability to use descriptive vocabulary and creative analogies and metaphors to illustrate ideas and techniques to students and to relate explanations to student's interests and life outside education. Teachers reported further that they had faith in their abilities to incorporate alternative instructional methods in their classrooms $(\mathrm{M}=3.37$; $\mathrm{SD}=0.62)$. This creates the impression that theycan guarantee that students understandwhat they are supposed to do during the classes

Concerning GHL teachers' efficacy in classroom management, it was found that they had control over disruptive behaviours ( $M=3.34 ; \mathrm{SD}=0.48)$, they could calm a student who is disruptive or noisy in the classroom $(M=3.20 ; S D=0.68)$, get their students to follow classroom and school rules $(\mathrm{M}=3.17 ; \mathrm{SD}=0.54)$ and establish a classroom management system with each group of students $(M=3.15 ; \mathrm{SD}=0.62)$. These findings indicate that GHL teachers could set up an organized classroom climate and make the classroom atmosphere feel business-like and efficient, without being authoritarian in order for students to be able to participate deeply in content.

It is concluded from these results that on average, the GHL teachers had a high level of teaching self-efficacy $(\mathrm{MM}=3.39$; $\mathrm{SD}=0.27)$. This was evident by the mean score which is within the mean criterion of 2.50-4.00. This result means that the GHL teachers had a high level of teaching self-efficacy in student engagement, instructional strategies and classroom control, and management. Thus, they had a high level of confidence in their ability to engage students in instructional discourse, provide and use appropriate instructional pedagogies and action systems during teaching and learning, and ensure effective classroom control and management to avoid class interruption during teaching and learning. The result of this study aligns with other studies in the Ghanaian context. It is consistent with the findings of Sarfo et al. (2015) which indicate that SHS teachers in Kumasi Metropolis typically had a high degree of self-efficacy. It also aligns 
with the findings of Kahraman et al. (2014) which found that pre-service teachers have very strong self-efficacy beliefs in science teaching.

\subsection{The Difference in GHL Teachers' Self-Efficacy Beliefs Based on Gender, Age, and Teaching Experience}

The objective of research hypothesis two was to identify whether there was any statistically significant difference in the self-efficacy beliefs among GHL teachers based on gender, age, and teaching experience. The data was analyzed and discussed using an independent sample t-test and One-way ANOVA because there is no significant interactions effect of the independent variables (gender, age, and teaching experience) on teachers' self-efficacy beliefs. The results are presented in Table 4.

\begin{tabular}{|c|c|c|c|c|c|c|c|}
\hline Variable & Group & N & Mean & SD & t/f-value & df & Sig. \\
\hline Gender & Male & 26 & 3.41 & 0.19 & 0.524 & 39 & 0.603 \\
& Female & 15 & 3.36 & 0.38 & & & \\
\hline Age & Between 30-34yrs & 4 & 3.13 & 0.70 & & & \\
& Between 35-39yrs & 8 & 3.47 & 0.16 & & & \\
& Between 40-44yrs & 10 & 3.33 & 0.14 & 1.529 & $4(36)$ & 0.214 \\
& Between 45-49yrs & 8 & 3.44 & 0.26 & & & \\
& Between 50yrs above & 11 & 3.45 & 0.14 & & & \\
\hline Teaching & Between 1-5yrs & 2 & 3.38 & 0.18 & \multirow{3}{*}{1.379} & $3(37)$ & \multirow{3}{*}{0.264} \\
experience & Between 6-10yrs & 18 & 3.30 & 0.32 & & & \\
& Between 11-15yrs & 7 & 3.43 & 0.13 & & & \\
& Between 16-20yrs & 14 & 3.49 & 0.24 & & & \\
\hline
\end{tabular}

Table 4: Differences in GHL Teachers' Self-Efficacy Based on Demographic Characteristics Source: Field data, 2020

Table 1 shows the results of the differences in GHL teachers' self-efficacy beliefs based on gender, age group, and teaching experience. Concerning the teachers' gender and their self-efficacy beliefs, it appears that the male teachers $(M=3.41 ; S D=0.19)$ had a high level of self-efficacy than the female teachers $(M=3.36 ; S D=0.38)$. However, the results of the independent samples t-test revealed that there was no statistically significant difference in the teachers' self-efficacy score for male and female teachers, $\mathrm{t}(39)=0.524, \mathrm{p}=0.603$. Thus, both male and female teachers had an equal level of selfefficacy towards their fidelity in curriculum implementation. Hence, the gender of a teacher is not a significant factor that could affect their self-efficacy towards fidelity in curriculum implementation.

This result confirmed the study of Mitchual et al. (2010) which reveal that the self-efficacy beliefs of pre-service teachers do not significantly differ according to gender. Similarly, it concurs with Karimvand (2011) who found that gender had no significant interaction effect on the participants' efficacy.

In Table 4, regarding age difference in teachers' self-efficacy, it seems to suggest that there were differences in the mean score of the teachers based on their age group. The teachers within the age group of 35-39 years had a high level of self-efficacy ( $M=3.47 ; S D=0.16)$. This was followed by the teachers within the age group of 50years and above $(M=3.45$; $S D-0.14)$, those in the age group of $45-49$ years $(M=3.44 ; S D=0.26)$, those in the age group of 40-44years $(M=3.33$; $\mathrm{SD}=0.14$ ) while the teachers in the age group of 30-34years appear to have the low self-efficacy. However, the results of One-Way ANOVA revealed that there was no statistically significant difference in teachers' self-efficacy beliefs, $F(4,36)=$ $1.529, \mathrm{p}=0.214$. This result means teachers' self-efficacy beliefs are not sensitive to their age distribution. The teachers with the age range of 30 years to 50years and above have equal self-efficacy towards fidelity in curriculum implementation.'

These results are consistent with the study of Voris (2011) which also revealed that there are no significant differences in the self-efficacy levels of special education teachers when analyzed by age. Again, the findings appear to be in line with Hicks (2012) and Tweed (2013) who found no sufficient evidence to indicate a relationship between selfefficacy and teachers' age.

From Table 4, teachers' self-efficacy and years of teaching experience, the mean scores appear to suggest that there is a difference in the self-efficacy among teachers based on teaching experience. For example, the teachers who had taught for about 16-20years $(M=3.49 ; \mathrm{SD}=0.24)$ had a high level of self-efficacy towards their fidelity in curriculum implementation compared with those who had taught for about 11-15years ( $M=3.43 ; S D=0.13)$, those with 6-10years (3.30; $\mathrm{SD}=0.32$ ) teaching experience and $1-5$ years $(\mathrm{M}=3.38$; $\mathrm{SD}=0.18)$. However, the results of One-Way ANOVA indicated that there was no statistically significant difference in teachers' self-efficacy beliefs based on years of teaching experience. This result means that teachers' self-efficacy beliefs are not sensitive to years of teaching experience.

These findings confirm previous studies (Fives \&Buehl, 2010; Gür et al., 2012; Gowrie \&Ramdass, 2014; Alrefaei, 2015; Jaggernauth\& Jameson-Charles, 2015) which suggest that there is no significant association between the effectiveness of teachers and years of teaching experience.

\subsection{The Effect of Teachers' Self-efficacy Beliefs on Curriculum Implementation}

The objective of research hypothesis one was to examine whether there was any statistically significant effect of GHLteachers' self-efficacy beliefs on curriculum implementation in the senior high schools. The data were analyzed and discussed using multiple linear regression. The statistical results have been presented in Table 5. 


\begin{tabular}{|c|c|c|c|c|c|c|c|}
\hline Variable & B & SE & Beta & $\mathbf{t}$ & sig & $\mathbf{T}$ & VIF \\
\hline (Constant) & 0.984 & 0.557 & & 1.768 & 0.085 & & \\
\hline Student engagement & 0.388 & 0.125 & 0.395 & 3.116 & 0.004 & 0.990 & 1.011 \\
\hline Instructional strategies & 0.502 & 0.126 & 0.615 & 3.996 & 0.000 & 0.672 & 1.488 \\
\hline Classroom management & 0.326 & 0.128 & 0.395 & 2.554 & 0.015 & 0.667 & 1.498 \\
\hline $\begin{array}{c}\text { R } \\
\text { R square } \\
\text { Adj R square }\end{array}$ & \multicolumn{2}{|c|}{$\begin{array}{l}=0.641 \\
=0.410 \\
=0.363\end{array}$} & & \multicolumn{2}{|c|}{$\begin{array}{c}\text { F }(3,37) \\
\text { Sig. } \\
\text { DW }\end{array}$} & \multicolumn{2}{|c|}{$\begin{array}{l}=8.584 \\
=0.000 \\
=1.554\end{array}$} \\
\hline
\end{tabular}

Table 5: Regression Analysis of Effect of GHL Teachers' Self-Efficacy Beliefs on Fidelity in

Curriculum Implementation

Source: Field Data, 2020 T= Tolerance $\quad$ VIF= Variance Inflation Factor

Table 5 shows the results of the multiple linear regression analysis of the effect of GHL teachers' self-efficacy belief on fidelity in curriculum implementation. The independent variable was the Teacher-Self-Efficacy Scale (student engagement, instructional strategies, and classroom management) and the outcome variable was Teacher Fidelity in curriculum implementation). The DW value of 1.554 is within the value of 0 and 4 . The value of 1.554 which is approximately 2.00 indicates that there is no self-correlation which is positive self-correlation. This means that the residuals from an ordinary least-squares regression are not self-correlated. The Tolerance and VIF are for diagnosing multicollinearity in the multiple regression analysis. They are based on the R-square value. The value of Tolerance for all the independent variables is greater than 0.10 to 0.40 as suggested by researchers (Menard, 1995; Allison, 1999; Hair et al., 2010). It is also evident from the results that VIF values are less than 4.0 to 10 (Kennedy, 1992; Rogerson, 2001; Hair et al, 2017) hence, there is no multicollinearity among the self-efficacy beliefs scale (student engagement, instructional strategies, and classroom management).

In Table 5, it was found that the GHL teachers' self-efficacy (student engagement, instructional strategies and classroom management) statistically significantly predicted their fidelity in curriculum implementation, $F(3$. 37) $=8.584$, $p<0.001, R=0.641$ with $R^{2}=0.410$. This explains that all the three interdependent variables (student engagement, instructional strategies, and classroom management) significantly contributed to fidelity in curriculum implementation. The R-value of 0.641 represents the multiple correlation coefficient which measures the quality of the prediction of the dependent variable (teacher fidelity in curriculum implementation). The R-square $\left(\mathrm{R}^{2}\right)$ value $(0.410)$ which is the coefficient of determination explains about $41 \%$ of the variance in the dependent variable (teacher fidelity in curriculum implementation).

From Table 5, the regression model indicates that the constant was $(B=0.9844, S E=0.557, t=1.768, p=0.085)$. This means the Ghanaian language curriculum would be implemented at 0.984 if teacher self-efficacy variables (student engagement, instructional strategies, and classroom management) are held constant or zero. This means that GHL teachers would positively implement the Ghanaian language and Culture curriculum if their efficacy beliefs are held constant. From the model, GHL teachers' efficacy in InstructionalStrategies (B=0.502; SE=0.126, t=3.996, p < 0.001) are highest significant predictor of fidelity in curriculum implementation. The result implies that if GHL teachers increase their instructional strategies, they would significantly and positively implement the Ghanaian language curriculum in the school by $50.2 \%$ changes. This was followed by their Efficacy in Student Engagement $(B=0.388, S E=0.125, t=3.116, p=0.004)$. This result means that if GHLteacher engages their students by a percent change, they would significantly and positively implement the curriculum by $38.8 \%$ while their Efficacy in Classroom Management $(\mathrm{B}=0.326 ; \mathrm{SE}=0.128 ; \mathrm{t}=0.2554, \mathrm{p}=0.015)$ would contribute about $32.6 \%$ in the curriculum implementation.

It could be inferred from these results that GHL teachers' self-efficacy beliefs significantly and positively predict their fidelity in curriculum implementation. The most predictor was their Efficacy in Instructional Strategies, followed by Efficacy in Student Engagement and Classroom Management. These findings validate previous research that self-efficacy is favourably correlated with teachers in terms of their contribution to teaching classroom preparation and coordination (Allinder, 1994; Dibapile, 2012), and classroom management (Poulou, 2007; Woolfolk \& Hoy, 1990; Woolfolk, Rosoff\& Hoy, 1990). The results also corroborated other studies that teacher self-efficacy is related to the ability of educators to adopt novel instructional techniques (Guskey, 1988; Czerniak\&Chiarelott, 1990).

\section{Conclusions and Recommendations}

The study concludes that GHL teachers faithfully implement the Ghanaian Language and Culture curriculum considering the fact that they are able to effectively set instructional objectives, teach the curriculum content appropriately, and also vary their instructional strategies as well as assessment activities in the curriculum as prescribed by the National Council for Curriculum Assessment NaCCA.

As regards the research hypotheses, the conclusions drawn are that GHL teachers' self-efficacy predicts their effectiveness in implementing the Ghanaian Language and Culture curriculum. It could also be concluded that demographic variables of teachers do not determine their efficacy in implementing the Ghanaian Language and Culture curriculum.

Based on the findings of the study it is recommended GHL teachers should continue to increase their self-efficacy in Student Engagement, Instructional Strategies, and Classroom Management by attending more in-service training like workshops and Conferences centered on making them more efficacious. 


\section{References}

i. Allinder, R. M. (1994). The relationship between efficacy and the instructional practices of special education teachers and consultants. Teacher Education and Special Education, 17(2), 86-95.

ii. Allison, P. D. (1999), Multiple Regression - A Primer, Thousand Oaks, CA: Pine Forge Press

iii. Alrefaei, N. A. (2015). Teachers' sense of efficacy: Examining the relationship of teacher efficacy and student achievement. Unpublished doctoral dissertation, University of Arkansas, Fayetteville.

iv. Asare-Danso, S. (2011). Pupils' attitudes towards Religious and Moral Education: A survey of junior high school pupils in Cape Coast, Ghana. International Journal of Basic Education, 1(1), 111-121.

v. Bandura, A. (1982). Self-efficacy mechanism in human agency. American Psychologist, 37(2), 122-147.

vi. Bandura, A. (1993). Perceived self-efficacy in cognitive development and functioning. Educational psychologist, 28(2), 117-148.

vii. Bandura, A. (1997). Self-efficacy: The exercise of control. New York, NY: Freeman.

viii. Bruce, C. D., Esmonde, I., Ross, J., Dookie, L., \& Beatty, R. (2010). The effects of sustained classroom-embedded teacher professional learning on teacher efficacy and related student achievement. Teaching and Teacher education, 26(8), 1598-1608.

ix. Caprara, G. V., Barbaranelli, C., Borgogni, L., \&Steca, P. (2003). Efficacy beliefs as determinants of teachers' job satisfaction. Journal of Educational Psychology, 95(4), 821-832.

x. Chalmers, D. (2004). The representational character of experience. The future for philosophy, 153-181.

xi. Cobbold, C. (1999). Implementation of the social studies program in teacher training colleges in Ghana: An Evaluation. Unpublished doctoral dissertation, University of Cape Coast, Cape Coast.

xii. Coladarci, T. (1992). Teachers' sense of efficacy and commitment to teaching. The Journal of Experimental Education, 60(4), 323-337.

xiii. Czerniak, C., \&Chiarelott, L. (1990). Teacher education for effective science instruction-A social cognitive perspective. Journal of Teacher Education, 41(1), 49-58.

xiv. Dibapile, W. T. S. (2012). Teacher efficacy and classroom management among Botswana junior secondary school teachers. Unpublished doctoral dissertation, University of Tennessee, Knoxville, USA.

xv. Eminah, J. K. (1993). The implementation of the JSS science curriculum: A study of the alignment of prescribed approaches to teaching and learning and actual practice. Unpublished master's thesis, University of Cape Coast, Cape Coast.

xvi. Fives, H., \&Buehl, M. (2010). Examining the factor structure of the teachers' sense of efficacy scale. The Journal of Experimental Education, 78(1), 118-134.

xvii. Fullan, M. (1994). Implementation of innovations. In T. Husen and T. N. Postlethwaite (Eds.). The International Encyclopedia of Education (2nd ed. pp. 2839-2847). Oxford: Pergamon Press, 2839-2847.

xviii. Ghaith, G., \&Yaghi, H. (1997). Relationships among experience, teacher efficacy, and attitudes toward the implementation of instructional innovation. Teaching and Teacher education, 13(4), 451-458.

xix. Gibson, S., \& Dembo, M. H. (1984). Teacher efficacy: A construct validation. Journal of Educational Psychology, 76(4), 569-582.

xx. Gowrie, G., \&Ramdass, M. (2014). Dimensions of teacher efficacy and student academic achievement in selected primary schools in Trinidad and Tobago. Journal of Education, Society and Behavioural Science, 4(10), 1358-1371.

xxi. Gur, G., ÇakırOğLU, J., \& Aydın, Y. Ç. (2012). Investigating predictors of sense of efficacy believes of classroom, science, and mathematics teachers. Education and Science, 37(166), 68-76.

xxii. Guskey, T. R. (1988). Teacher efficacy, self-concept, and attitudes toward the implementation of instructional innovation. Teaching and Teacher Education, 4(1), 63-69.

xxiii. Hair Jr, J. F., Hult, G. T. M., Ringle, C., \&Sarstedt, M. (2017). A primer on partial least squares structural equation modelling (PLS-SEM). Sage publications.

xxiv. Hair Jr. J. F, Black WC, Babin BJ, Anderson RE (2010). Multivariate Data Analysis: A Global Perspective (7th ed.). New Jersey: Pearson Education Inc.

xxv. Hicks, S. (2012). Self-efficacy and classroom management: A correlation study regarding the factors that influence classroom management. Unpublished dissertation, Liberty University, Lynchburg, VA.

xxvi. Hoy, W. K., \& Woolfolk, A. E. (1993). Teachers' sense of efficacy and the organizational health of schools. The Elementary School Journal, 93(4), 355-372.

xxvii. Jaggernauth S., \& Jameson-Charles, M (2015). An investigation of the influence of teacher variables on pretraining efficacy beliefs. The Caribbean Teaching Scholar, 5(1), 5-24.

xxviii. Kahraman, S., Yilmaz, Z. A., Bayrak, R., \&Gunes, K. (2014). Investigation of pre-service science teachers' selfefficacy beliefs of science teaching. Procedia-Social and Behavioural Sciences, 136, 501-505.

xxix. Karimvand, P. N. (2011). The nexus between Iranian EFL teachers' self-efficacy, teaching experience, and gender. English Language Teaching, 4(3), 171-183.

xxx. Kennedy, G. F. (1992). Quality in grandparent=grandchild relationships. International Journal of Aging and Human Development, 35, 83-98.

xxxi. Kwarteng, J. T. (2013). Quality in senior high school accounting education in Ghana. Unpublished doctoral dissertation, University of South Africa.

xxxii. Leung, W. L. A. (2008). Teacher concerns about curriculum reform. The Asia-Pacific Education Researcher, 17(1), 75-97.

xxxiii. Lewy, A. (1991). The international encyclopaedia of curriculum (Ed.). New York: Pergamon Press. 
xxxiv. Marsh, C. J. (1997). Key concepts for understanding curriculum 2: Planning, management \& ideology. London: Falmer Press.

xxxv. Marsh, C. J., \& Willis, G. (2007). Curriculum: Alternative approaches, ongoing issues. Upper Saddle River, NJ: Pearson.

xxxvi. Mazze, C. E. (2013). Teacher self-efficacy and student learning: A case study of the implementation of Common Core State Standards in mathematics in a parochial middle school. Unpublished doctoral dissertation, The University of North Carolina at Charlotte.

xxxvii. Menard, S. (1995) 'Applied Logistic Regression Analysis: Sage University Series on Quantitative Applications in the Social Sciences', Thousand Oaks, CA: Sage.

xxxviii. Mereku, K. D. (1995). A comparison of the official primary mathematics curriculum in Ghana with the way in which it is implemented by teachers. Unpublished Doctoral dissertation, University of Leeds.

xxxix. Midgley, C., Feldlaufer, H., \& Eccles, J. S. (1989). Change in teacher efficacy and student self-and task-related beliefs in mathematics during the transition to junior high school. Journal of Educational Psychology, 81(2), 247258.

xl. Milner, H. R. (2001). A qualitative investigation of teachers' planning and efficacy for student engagement. The Ohio State University.

xli. Mitchual, S. J., Donkor, F. and Quansah, C. (2010). The relationship between self-efficacy beliefs and performance of pre-service teacher interns. Ghana Journal of Education and Teaching, 11, 268 - 282.

xlii. Okrah, A. K. (2002). Fidelity approach to curriculum implementation: A case of transacting the core English curriculum in senior secondary schools in the BrongAhafo Region of Ghana. Unpublished doctoral dissertation, University of Cape Coast).

xliii. Oliva, P. F. (1992). Developing the curriculum. (3 ${ }^{\text {rd }}$ ed.). NY: Harper Collins Publishers, Inc.

xliv. Osuala, E. C. (2001). Introduction to research methods. Onitsha, Nigeria: African FEP publishers.

xlv. Owusu, A. A. (2012). Fidelity approach to implementing the senior high school French curriculum among selected schools in the Takoradi metropolis. Unpublished master's thesis, University of Cape Coast, Cape Coast.

xlvi. Poulou, M. (2007). Personal teaching efficacy and its sources: Student teachers' perceptions. Educational Psychology, 27(2), 191-218.

xlvii. Rogerson, P. A. (2001). Statistical methods for geography. London, England: Sage.

xlviii. Sarfo, F. K., Amankwah, F., Sam, F. K., \& Konin, D. (2015). Teachers' self-efficacy beliefs: The relationship between gender and instructional strategies, classroom management, and student engagement. Ghana Journal of Development Studies, 12(1-2), 19-32.

xlix. Smith, A. B. (1996). The early childhood curriculum from a sociocultural perspective. Early Child Development and Care, 115(1), 51-64.

1. Snyder, J., Bolin, F. \& Zumwalt, K. (1992).Curriculum implementation. In P. W. Jackson (Ed.). Handbook of research on curriculum. New York: Macmillan, 402-433.

li. Torto, G. A. (2017). The implementation of the basic school English curriculum: The case of the Cape Coast Metropolis in Ghana. Journal of Education and Practice, 8(8), 166-175.

lii. Tschannen-Moran, M., \& Hoy, A. W. (2001). Teacher efficacy: Capturing an elusive construct. Teaching and Teacher Education, 17(7), 783-805.

liii. Tweed, S. R. (2013). Technology implementation: Teacher age, experience, self-efficacy, and professional development as related to classroom technology integration. Unpublished doctoral dissertation, Faculty of the Department of Educational Leadership and Policy Analysis, East Tennessee State University.

liv. Wolf, K. J., Foster, D. D., \& Birkenholz, R. J. (2010). The Relationship between teacher self-efficacy and the professional development experiences of agricultural education teachers' candidates. Journal of Agricultural Education, 51(4), 38-48.

lv. Wolters, C. A., \& Daugherty, S. G. (2007). Goal structures and teachers' sense of efficacy: Their relation and association to teaching experience and academic level. Journal of Educational Psychology, 99(1), 181-193.

lvi. Woolfolk, A. E., \& Hoy, W. K. (1990). Prospective teachers' sense of efficacy and beliefs about control. Journal of Educational Psychology, 82(1), 81-91.

lvii. Woolfolk, A. E., Rosoff, B., \& Hoy, W. K. (1990). Teachers' sense of efficacy and their beliefs about managing students. Teaching and teacher Education, 6(2), 137-148. 